\title{
Breast-feeding at 12 months of age and dietary habits among breast-fed and non-breast-fed infants
}

\author{
Britt Lande $1,2, *$, Lene Frost Andersen ${ }^{2}$, Marit B Veierød ${ }^{3}$, Anne Bærug ${ }^{4}$, Lars Johansson ${ }^{1}$, \\ Kerstin U Trygg ${ }^{2}$ and Gunn-Elin Aa Bjørneboe ${ }^{1}$ \\ 'Directorate for Health and Social Affairs, Department for Nutrition, PO Box 8054 Dep, N-0031 Oslo, Norway: \\ ${ }^{2}$ Institute for Nutrition Research, University of Oslo, Norway: ${ }^{3}$ Section of Medical Statistics, University of Oslo, \\ Norway: ${ }^{4}$ National Breastfeeding Centre, Oslo, Norway
}

Submitted 25 June 2003: Accepted 2 October 2003

\begin{abstract}
Objective: To analyse factors associated with breast-feeding and use of sweetened drinks at 12 months, and to compare dietary habits among breast-fed and non-breastfed infants.

Design: Data were collected by a semi-quantitative food-frequency questionnaire filled in by the parents.

Setting: National dietary survey in Norway.

Subjects: In total, 1932 12-month-old infants were included.

Results: At 12 months, 36\% of the infants were breast-fed. The odds of breast-feeding at this age were more than doubled both for mothers $\geq 35$ years compared with mothers $<25$ years and for mothers in the highest educational group compared with mothers in the lowest. A negative association was found for maternal smoking, and the odds of breast-feeding were $40 \%$ lower for mothers who smoked than for nonsmokers. Some dietary differences were observed between breast-fed and nonbreast-fed infants apart from intake of milk. In particular, breast-fed infants had a significantly lower daily intake of sweetened drinks than non-breast-fed infants and a $16 \%$ lower mean daily intake of added sugars $(P<0.001)$. Furthermore, breast-fed infants had 30\% higher odds of not receiving sweetened drinks daily, compared with non-breast-fed infants.

Conclusions: Maternal age, education and smoking status were important factors for breast-feeding at 12 months. Breast-fed infants had lower intakes of sweetened drinks and added sugars than non-breast-fed infants. From a public health perspective, continued promotion of breast-feeding is needed to reduce inequalities in breastfeeding. Moreover, prevention of high intakes of sweetened drinks and added sugars should start in infancy.
\end{abstract}

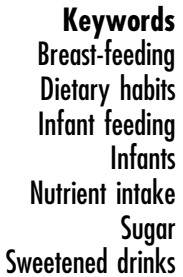

Breast-feeding is recommended along with nutritionally adequate complementary feeding throughout the first year of life or longer in Norway ${ }^{1}$, while the World Health Organization (WHO) recommends breast-feeding for at least 24 months $^{2}$. Today, breast-feeding rates are considerably higher in Norway than in many other Western countries ${ }^{3}$. However, increased knowledge of the factors associated with breast-feeding until at least 12 months is important for continued breast-feeding promotion and to reduce inequalities in breast-feeding.

Those who are breast-fed during the first 12 months of life may have different dietary habits, apart from receiving breast milk, than those not breast-fed at this age. There are some data on dietary differences between breast-fed and non-breast-fed infants in the second half of infancy, when other foods and drinks become an increasingly larger part of the diet ${ }^{4-9}$. However, most of these studies have focused on intakes of energy, protein and fat in relation to infant growth, and less on intakes of foods, drinks, added sugars or micronutrients. Data from a more detailed evaluation of dietary differences between breast-fed and non-breast-fed infants will provide useful baseline data for counselling and the promotion of healthy infant feeding practices.

Data suggest that breast-feeding may reduce the risk of childhood obesity ${ }^{10,11}$, while consumption of sugarsweetened drinks in childhood may increase the risk ${ }^{12}$. High intakes of sweetened drinks and sugars among children may also have a negative effect on the nutrient quality of the $\operatorname{diet}^{13}$ as well as on dental health ${ }^{14}$. The Nordic countries recommend ${ }^{15}$, in accordance with $\mathrm{WHO}^{16}$, that intake of sugar should not exceed $10 \%$ 
of total energy intake. In a recent national dietary survey, it was found that more than $80 \%$ of Norwegian 4-year-olds had an intake of added sugars above this level, and sweetened drinks were the main source of sugar ${ }^{17}$. Moreover, national survey data from the USA show increasing intakes of soft drinks with age in childhood ${ }^{18}$. Increased knowledge of the factors associated with breastfeeding throughout infancy and the use of sweetened drinks in early childhood is essential in counselling and for the promotion of healthy dietary habits, and may also be of importance in efforts to prevent a high sugar intake and obesity in later life.

The objective of the present work was to analyse factors associated with breast-feeding and the use of sweetened drinks in a large nation-wide sample of 12-month-old infants, and to compare dietary habits among breast-fed and non-breast-fed infants.

\section{Subjects and methods}

\section{Subjects and design}

A sample of 3000 Norwegian infants was established by Statistics Norway ${ }^{19}$, and included all infants born in Norway during a 3-week period from 27 April until 17 May 1998 to mothers born in Norway or another Scandinavian country. The infant's mother/parents were invited to participate when their child was 6 and 12 months of age. This was the first national survey on infant feeding in Norway. At 6 months, 2383 (80\%) participated. Some of the non-responders at 6 months $(n=46)$ gave a written refusal to participate, and these were not invited at 12 months. Furthermore, a few $(n=3)$ were not found when updating against the national register. Thus, a total of 2943 infants were invited to participate at 12 months.

The survey was carried out in April-June 1999. The mothers received an invitation and a semi-quantitative food-frequency questionnaire (SFFQ) by mail about 2 weeks before the infants turned 1 year old. To obtain data on the child's weight and length, parents were asked to bring the questionnaire to the regular 12-month check-up at the child's health clinic, and then return the completed questionnaire in a pre-paid envelope. Statistics Norway was responsible for data collection. The Regional Ethics Committee for Medical Research approved the study, and written informed consent was obtained from the parents. A more detailed description of the sample and design has been published previously ${ }^{3}$.

\section{The semi-quantitative food-frequency questionnaire}

The SFFQ has been described in more detail elsewhere ${ }^{20}$. Briefly, it covered 16 pages, was optical mark readable and included questions on breast-feeding, use of food and drink items, other food habits, use of vitamin/mineral supplements and background variables. The frequency alternatives varied from never/less than once per week to several times per day for drinks, porridges, potatoes, vegetables, fruit, berries, commercial infant food, yoghurt and vitamin/mineral supplements, and from never/less than once per month to several times per week for other foods. Intake of bread was reported as slices per day or never/not weekly. Infants consuming a food or drink at least once a week, or alternatively at least once a month, were defined as consumers. A booklet including 16 colour photograph series with four different portion sizes was used when reporting amounts of food and drink eaten. When no photograph was available for a food item, household units, such as slices, pieces and spoons, were used. The SFFQ also included questions on weight and length at birth and 12 months, mother's and father's highest educational level, gestational age, number of children the mother had, allergy/asthma among family members, maternal employment status and day care. The SFFQ has been validated against weighed records ${ }^{20}$.

\section{Otber data collected}

Statistics Norway provided data from the Central Population Register on infant gender, maternal age, marital status and region. Data on maternal smoking and degree of urbanisation were provided from the 6-month survey.

\section{Nutrient calculations}

Daily intakes of foods, drinks, energy and nutrients were computed using a food database and a software system developed at the Institute for Nutrition Research, University of Oslo. The food database is based mainly on the official food composition table $\mathrm{e}^{21}$, and is continuously supplemented with data on new food items and nutrients. Corrections for losses in cooking are done when calculating nutrient contents. The use of cod liver oil and vitamin/mineral supplements is included in the nutrient calculations. The term 'added sugars' refers to refined or industrially produced sugars used as an ingredient in processed or prepared foods or added at home in the kitchen or at the table. Added sugars do not include naturally occurring mono- and disaccharides in fruit, juices and milk.

\section{Statistical analyses}

Intakes of foods and drinks are presented as means, medians and 25th and 75th percentiles, and the MannWhitney $U$-test was used to compare intakes between groups. Nutrient intakes are presented as means with standard deviations (SDs), breast-feeding frequency as mean with 95\% confidence interval (CI), and comparisons between groups were performed using Student's $t$-test. Furthermore, a chi-square test was used to compare proportions between groups. For proportions, 95\% CIs were calculated by using the normal approximation to the binomial distribution.

Intakes of foods, drinks, energy and nutrients are presented combined for boys and girls. The differences 
in consumption between breast-fed and non-breast-fed infants when data were analysed separately for boys and girls were comparable with the differences observed when the data were combined (data not shown).

Multiple logistic regression analysis was applied to study the healthy habits of breast-feeding and no daily use of sweetened drinks at 12 months in relation to selected maternal and infant characteristics. The results are presented as crude and adjusted odds ratios with 95\% CIs. Statistical significance was tested by the likelihood ratio test. Potential interaction effects were examined. The test for trend across categories was performed by treating the categories as a continuous variable. Both mother's and father's highest educational level were categorised as $\leq 10$ years, $11-12$ years and $\geq 13$ years in the logistic regression analyses. Maternal age and marital status were categorised as $<25$ years, 25-34 years and $\geq 35$ years, and as married, cohabitant and not married/cohabitant, respectively. Degree of urbanisation was coded according to the number of inhabitants, $<2000$, 2000-19999, 20000-99999 and $\geq 100000$, and geographic region as Capital and surroundings, East region, South, West, Middle and North region. Gestational age was reported as $<38$ week or $\geq 38$ week. The number of children the mother had was reported as 1 child, 2,3 or $\geq 4$ children and then collapsed and redefined into number of siblings: 0,1 and $\geq 2$ siblings. Allergy/asthma among family members was categorised as yes (the infant's mother, father and/or sibling(s) had or have had allergy/asthma) or no, and maternal employment status when the child was 12 months old as not working, working part-time and working full-time. Day care by persons other than the parents (all or some weekdays, as number of days was not registered) was categorised as yes or no, and infant birth weight as $<2500 \mathrm{~g}, 2500-3500 \mathrm{~g}$ and $>3500 \mathrm{~g}$. Data on maternal smoking were recorded only when the child was 6 months old, and coded as yes or no. We used both univariate analyses (with a lax criterion of $P<0.10$ ) and evidence from the literature to decide which variables should be examined in the multivariate analyses. The final models include only significant variables $(P<0.05)$ or variables where the literature suggests importance.

All $P$-values are two-sided, and a 5\% level of significance was used. All statistical analyses were performed with SPSS 11.0 (SPSS Inc., Chicago, IL, USA).

\section{Results}

Questionnaires were received from 1934 (66\%) of the 2943 invited infants. Two of these questionnaires were incomplete and excluded. Thus the final study sample included 1932 infants. The mothers completed 91\% of the questionnaires, $8 \%$ were filled in by both parents and $1 \%$ by the fathers. Selected characteristics of the infants and their parents are presented in Table 1.
Table 1 Infant, maternal and paternal characteristics

\begin{tabular}{|c|c|c|}
\hline Characteristic & $n$ & Value* $^{*}$ \\
\hline \multicolumn{3}{|l|}{ Infants } \\
\hline Boys/girls & 1932 & $53 / 47$ \\
\hline Weight at 12 months $(\mathrm{g})$ & 1906 & \\
\hline Boys & 1005 & $10367(1126)$ \\
\hline Girls & 901 & 9584 (1089) \\
\hline Length at 12 months $(\mathrm{cm})$ & 1907 & \\
\hline Boys & 1007 & $77(3)$ \\
\hline Girls & 900 & $76(3)$ \\
\hline \multicolumn{3}{|l|}{ Mothers } \\
\hline Age (years) & 1932 & $29.8(4.8)$ \\
\hline Education (years) & 1876 & \\
\hline$\leq 10$ & 192 & 10 \\
\hline $11-12$ & 784 & 42 \\
\hline$\geq 13$ & 900 & 48 \\
\hline $\begin{array}{l}\text { Employment status when the child was } \\
12 \text { months old }\end{array}$ & 1830 & \\
\hline Not working & 978 & 53 \\
\hline Working part-time & 517 & 28 \\
\hline Working full-time & 335 & 18 \\
\hline Primiparous & 1914 & 40 \\
\hline Married/cohabitants & 1926 & 95 \\
\hline $\begin{array}{l}\text { Smoked when the child was } 6 \\
\text { months old }\end{array}$ & 1822 & 25 \\
\hline \multicolumn{3}{|l|}{ Fathers } \\
\hline Education (years) & 1717 & \\
\hline$\leq 10$ & 180 & 10 \\
\hline $11-12$ & 794 & 46 \\
\hline$\geq 13$ & 743 & 43 \\
\hline
\end{tabular}

* Percentages for categorical variables and means (standard deviations) for continuous variables.

\section{Breast-feeding}

At 12 months, 36\% (95\% CI 34-38\%) of the infants were breast-fed. A higher proportion of girls (39\%, 95\% CI 36$42 \%)$ than boys (34\%, 95\% CI 31-37\%) were breast-fed $(P=0.03)$. The mean breast-feeding frequency at this age was 3.7 times per $24 \mathrm{~h}(95 \%$ CI 3.5-3.8). There was no significant difference between boys and girls in breastfeeding frequency $(P=0.83)$.

\section{Factors associated with breast-feeding}

Maternal age, maternal education, maternal smoking, degree of urbanisation, day care and allergy/asthma among family members were significantly associated with breast-feeding at 12 months (Table 2). Significant positive trends were found for maternal age, maternal education and degree of urbanisation. The odds of breast-feeding were more than doubled both for mothers aged $\geq 35$ years compared with mothers $<25$ years old and for mothers in the highest educational group compared with mothers in the lowest. Mothers who smoked (when the child was 6 months old) had about $40 \%$ lower odds of breast-feeding than mothers who were non-smokers. Furthermore, the odds of being breast-fed at 12 months was about $40 \%$ higher both for infants who did not have day care by persons other than the parents compared with those who had such day care, and for infants with parent(s) and/or sibling(s) affected with allergy/asthma than for those not affected. Infant gender was not significantly associated 
Table 2 Crude and adjusted odds ratio (OR) (and 95\% confidence interval $(\mathrm{CI})$ ) for breast-feeding at 12 months according to maternal and infant characteristics*

\begin{tabular}{|c|c|c|c|}
\hline \multirow[b]{2}{*}{ Characteristic } & \multicolumn{3}{|c|}{ Breast-feeding at 12 months } \\
\hline & $n(\%) \dagger$ & Crude OR $(95 \% \mathrm{Cl})$ & Adjusted OR $(95 \% \mathrm{Cl}) \ddagger$ \\
\hline \multicolumn{4}{|l|}{ Maternal age (years) } \\
\hline$<25$ & $53(24)$ & 1.00 & 1.00 \\
\hline $25-34$ & $451(36)$ & $1.80(1.30-2.51)$ & $1.45(1.03-2.05)$ \\
\hline$\geq 35$ & $145(48)$ & $2.98(2.03-4.37)$ & $2.36(1.58-3.51)$ \\
\hline$P$ for trend§ & & $<0.001$ & $<0.001$ \\
\hline \multicolumn{4}{|l|}{ Maternal education (years) } \\
\hline$\leq 10$ & $35(20)$ & 1.00 & 1.00 \\
\hline $11-12$ & $235(32)$ & $1.87(1.25-2.79)$ & $1.82(1.21-2.76)$ \\
\hline$\geq 13$ & $379(44)$ & $3.07(2.07-4.55)$ & $2.48(1.63-3.77)$ \\
\hline$P$ for trend§ & & $<0.001$ & $<0.001$ \\
\hline \multicolumn{4}{|l|}{ Maternal smoking at 6 months } \\
\hline No & $544(41)$ & 1.00 & 1.00 \\
\hline Yes & $105(24)$ & $0.47(0.37-0.60)$ & $0.57(0.44-0.74)$ \\
\hline$P \mathbb{q}$ & & $<0.001$ & $<0.001$ \\
\hline \multicolumn{4}{|l|}{ Degree of urbanisation } \\
\hline$<2000$ inhabitants & $196(32)$ & 1.00 & 1.00 \\
\hline 2000-19999 inhabitants & $135(35)$ & $1.15(0.88-1.51)$ & $1.07(0.81-1.41)$ \\
\hline $20000-99999$ inhabitants & $92(38)$ & $1.29(0.95-1.76)$ & $1.19(0.86-1.64)$ \\
\hline$\geq 100000$ inhabitants & 226 (43) & $1.62(1.27-2.06)$ & $1.34(1.04-1.72)$ \\
\hline$P$ for trend§ & & $<0.001$ & 0.02 \\
\hline \multicolumn{4}{|c|}{ Day care by persons other than the parents } \\
\hline Yes & $203(32)$ & 1.00 & 1.00 \\
\hline No & 446 (39) & $1.35(1.10-1.66)$ & $1.43(1.15-1.77)$ \\
\hline$P q$ & & $<0.01$ & $<0.01$ \\
\hline \multicolumn{4}{|c|}{ Asthma/allergy among family members } \\
\hline No & $304(32)$ & 1.00 & 1.00 \\
\hline Yes & $345(41)$ & $1.47(1.21-1.78)$ & $1.40(1.14-1.71)$ \\
\hline$P q$ & & $<0.001$ & $<0.01$ \\
\hline \multicolumn{4}{|l|}{ Infant gender } \\
\hline Boy & 326 (35) & 1.00 & 1.00 \\
\hline Girl & $323(39)$ & $1.18(0.97-1.44)$ & $1.19(0.97-1.46)$ \\
\hline$P \|$ & & 0.09 & 0.09 \\
\hline
\end{tabular}

${ }^{*} n=1770$.

† Number of breast-fed infants at 12 months within current independent variable, percentages in parentheses.

$\ddagger$ ORs and $95 \%$ Cls adjusted for all other variables in the table.

$\S$ Test for linear trend.

१ Likelihood ratio test.

with breast-feeding in the multivariate analysis, but was considered scientifically relevant and therefore included in the final model. Degree of urbanisation and geographic region were significant only when one of them was included at a time. Degree of urbanisation was included in the final model, as this variable was considered to be most relevant.

\section{Comparison of dietary habits among breast-fed and non-breast-fed infants}

Data on daily intakes and percentages of consumers of various types of foods and drinks among breast-fed and non-breast-fed infants at 12 months are presented in Table 3. Breast-fed infants had significantly lower intakes of some foods, such as bread, meat/meat products, fish/fish products, commercial infant dinner products with meat or fish, yoghurt and margarine/butter, and a significantly higher intake of home-made porridge. However, the largest difference in consumption between breast-fed and non-breast-fed infants was seen for drinks. As expected, non-breast-fed infants had considerably higher intakes of infant formula and cow's milk, reflecting that breast milk was being replaced with other milk. Significant differences were also seen for other drinks; breast-fed infants had lower intakes of sugar-sweetened drinks, while their intake of water was higher.

Daily use of vegetables/potatoes was common (78\%) in both feeding groups, whereas $71 \%$ of breast-fed and $62 \%$ of non-breast-fed infants were daily consumers of fruit/berries. Daily use of sweetened drinks was less common among breast-fed (29\%) than among non-breastfed infants (36\%). Use of vitamin D supplements (cod liver oil or multivitamins containing vitamin D) was common among both breast-fed ( $76 \%$ daily or weekly consumers) and non-breast-fed infants $(72 \%$ daily or weekly consumers). Use of vitamin/mineral supplements other than vitamin D supplements was uncommon $(<3 \%)$ in both feeding groups.

Foods and drinks other than milk contributed a major part $(82 \%)$ to the total daily energy intake among nonbreast-fed infants. As we had no information on the amount of breast milk consumed, all milk (breast milk, infant formula and cow's milk) consumed as a drink was excluded to evaluate consequences on nutrient intakes resulting 
Table 3 Intakes of foods and drinks and percentages of consumers among breast-fed and non-breast-fed infants at 12 months

\begin{tabular}{|c|c|c|c|c|c|c|c|}
\hline & \multicolumn{4}{|c|}{ Intake $^{*}\left(\mathrm{~g} \mathrm{day}^{-1}\right)$} & \multirow[b]{3}{*}{$P$-value } & \multirow{2}{*}{\multicolumn{2}{|c|}{ Percentage of consumers }} \\
\hline & \multicolumn{2}{|c|}{ Breast-fed $(n=701)$} & \multicolumn{2}{|c|}{ Non-breast-fed $(n=1231)$} & & & \\
\hline & Mean & Median $\left(\mathrm{P}_{25}, \mathrm{P}_{75}\right)$ & Mean & Median $\left(\mathrm{P}_{25}, \mathrm{P}_{75}\right)$ & & Breast-fed & Non-breast-fed \\
\hline \multicolumn{8}{|l|}{ Foods } \\
\hline Porridge & 260 & $200(100,400)$ & 257 & $200(71,400)$ & 0.54 & 89 & 84 \\
\hline Commercial infant porridge & 224 & $200(43,400)$ & 226 & $200(43,400)$ & 0.95 & 79 & 77 \\
\hline Home-made porridge & 35 & $0(0,14)$ & 31 & $0(0,0)$ & 0.03 & 26 & 21 \\
\hline Bread & 55 & $51(27,77)$ & 64 & $57(30,90)$ & $<0.001$ & 97 & 98 \\
\hline Vegetables and potatoes $\ddagger$ & 93 & $75(38,125)$ & 97 & $77(39,126)$ & 0.52 & 94 & 95 \\
\hline Meat/meat products§ & 28 & $24(13,37)$ & 33 & $28(17,43)$ & $<0.001$ & 97 & 99 \\
\hline $\begin{array}{l}\text { Commercial infant dinner } \\
\text { with meat§q }\end{array}$ & 90 & $56(0,112)$ & 101 & $84(0,139)$ & 0.02 & 64 & 68 \\
\hline Fish/fish products & 8 & $5(0,12)$ & 11 & $8(2,16)$ & $<0.001$ & 69 & 80 \\
\hline $\begin{array}{l}\text { Commercial infant dinner } \\
\text { with fish }\end{array}$ & 9 & $0(0,0)$ & 14 & $0(0,0)$ & $<0.001$ & 13 & 22 \\
\hline Fruit and berries $\|$ & 94 & $75(41,124)$ & 90 & $75(38,117)$ & 0.25 & 98 & 96 \\
\hline Yoghurt & 52 & $31(0,86)$ & 66 & $36(13,94)$ & $<0.001$ & 72 & 79 \\
\hline Cheese & 10 & $7(2,14)$ & 11 & $7(2,14)$ & 0.68 & 80 & 79 \\
\hline Margarine and butter (as spreads) & 11 & $9(5,15)$ & 13 & $10(5,17)$ & $<0.001$ & 95 & 98 \\
\hline \multicolumn{8}{|l|}{ Drinks } \\
\hline Infant formula** & 30 & $0(0,0)$ & 153 & $0(0,240)$ & $<0.001$ & 14 & 38 \\
\hline Cow's milk** & 99 & $51(0,120)$ & 238 & $180(17,360)$ & $<0.001$ & 64 & 76 \\
\hline Whole milk (3.8\% fat) & 62 & $0(0,60)$ & 163 & $34(0,300)$ & $<0.001$ & 41 & 55 \\
\hline Semi-skimmed milk (1.5\% fat) & 35 & $0(0,17)$ & 72 & $0(0,34)$ & 0.64 & 31 & 28 \\
\hline Skimmed milk (0.1\% fat) & 2 & $0(0,0)$ & 2 & $0(0,0)$ & 0.77 & 2 & 2 \\
\hline Juice & 22 & $0(0,17)$ & 21 & $0(0,17)$ & 0.85 & $3 \overline{1}$ & $3 \overline{1}$ \\
\hline Commercial baby drinks & 13 & $0(0,0)$ & 14 & $0(0,0)$ & 0.72 & 15 & 15 \\
\hline Sugar-sweetened drinks & 59 & $17(0,77)$ & 93 & $34(0,120)$ & $<0.001$ & 56 & 68 \\
\hline Nectar & 13 & $0(0,0)$ & 18 & $0(0,17)$ & 0.04 & 23 & 27 \\
\hline Squash ('saft') & 44 & $0(0,43)$ & 72 & $17(0,120)$ & $<0.001$ & 49 & 58 \\
\hline Carbonated soft drinks & 3 & $0(0,0)$ & 3 & $0(0,0)$ & 0.72 & 11 & 11 \\
\hline Artificial sweetened squash & 7 & $0(0,0)$ & 20 & $0(0,0)$ & $<0.001$ & 8 & 14 \\
\hline Water & 206 & $180(120,300)$ & 191 & $120(60,240)$ & $<0.001$ & 95 & 89 \\
\hline
\end{tabular}

*Intake among all infants in the group; both consumers and non-consumers; Mean and median, with 25th and 75th percentiles $\left(P_{25}\right.$, $\left.P_{75}\right)$ in parentheses; data collected by a semi-quantitative food-frequency questionnaire.

† Mann-Whitney U-test.

$\ddagger$ Vegetables and potatoes in commercial infant food with meat or with fish are not included.

$\S$ Liver and liver products are included.

9 Vegetables and potatoes are included in commercial infant dinner with meat or with fish.

$\|$ Jam is not included.

** Infant formula and cow's milk in porridge and food preparation are not included.

from the differences in food and drink intakes. Breast-fed infants had 10\% lower mean daily intake of energy from foods and drinks other than milk compared with nonbreast-fed infants: 4049 (SD 1529) kJ and 4498 (SD 1589) kJ, respectively $(P<0.001)$. They had also significantly lower mean intakes of macronutrients and some micronutrients (vitamin A, thiamin, riboflavin, calcium and iron), whereas no significant differences were seen for vitamin $\mathrm{D}$, vitamin $\mathrm{E}$ and vitamin $\mathrm{C}$ (data not shown). The largest difference was seen for added sugars, breast-fed infants having a $16 \%$ lower mean daily intake than non-breast-fed infants: 27 (SD 20) $\mathrm{g}$ and $32(\mathrm{SD} 22) \mathrm{g}$, respectively $(P<0.001)$. When adjusting for energy intake, the difference in sugar intake was still significant $(P=0.05)$ (Table 4$)$. No significant difference was found for nutrient density of other macronutrients except for fibre, which was slightly higher among breast-fed infants. Furthermore, breast-fed infants had a $17 \%$ higher nutrient density of vitamin D than nonbreast-fed infants, and slightly higher nutrient densities of vitamin $\mathrm{E}$, vitamin $\mathrm{C}$, calcium and iron.

\section{Factors associated with no daily use of sweetened drinks}

Daily consumers of sweetened drinks were compared with no daily consumers/non-consumers. Sweetened drinks include sugar-sweetened squash, carbonated soft drinks and nectar (sugar-sweetened and water-diluted fruit juice). Breast-feeding at 12 months, number of siblings, maternal smoking and degree of urbanisation were significantly associated with no daily use of sweetened drinks (Table 5). The odds of no daily use of sweetened drinks were about 30\% higher for breastfed than for non-breast-fed infants. Furthermore, a significant negative trend was found for number of siblings, and the odds were about 30\% lower for infants of mothers who smoked (when their child was 6 months old) than for infants of mothers who were non-smokers. Maternal age and education were not significantly associated with no daily use of sweetened drinks in the multivariate model, but these variables were considered scientifically relevant and therefore included 
Table 4 Nutrient density of foods and drinks other than milk among breast-fed and non-breast-fed infants at 12 months

\begin{tabular}{lccc}
\hline & \multicolumn{2}{c}{ Nutrient density* } & \\
\cline { 2 - 3 } & $\begin{array}{c}\text { Breast-fed } \\
(n=701)\end{array}$ & $\begin{array}{c}\text { Non-breast-fed } \\
(n=1231)\end{array}$ & $P$-value† \\
\hline Percentage of energy & intake & & \\
Protein & $12.8(1.9)$ & $12.9(1.8)$ & 0.31 \\
Total fat & $30.2(5.9)$ & $30.5(5.7)$ & 0.19 \\
$\quad$ Saturated fatty acids & $8.9(3.7)$ & $9.0(3.5)$ & 0.34 \\
$\quad$ Monounsaturated & $7.3(2.9)$ & $7.3(2.7)$ & 0.65 \\
$\quad$ fatty acids & & & \\
$\quad$ Polyunsaturated & $4.8(2.6)$ & $5.0(2.6)$ & 0.10 \\
$\quad$ fatty acids & & & \\
Total carbohydrate & $57.0(6.1)$ & $56.6(5.9)$ & 0.11 \\
$\quad$ Added sugars & $11.4(6.2)$ & $12.1(6.5)$ & 0.05 \\
Content per 1 MJ & & & \\
Fibre $(\mathrm{g})$ & $3.3(0.7)$ & $3.1(0.7)$ & $<0.001$ \\
Vitamin A ( $\mu$ g) & $573(346)$ & $574(353)$ & 0.91 \\
Vitamin D ( $\mu$ g) & $2.1(1.6)$ & $1.8(1.5)$ & $<0.01$ \\
Vitamin E (mg) & $2.1(1.1)$ & $2.0(1.2)$ & 0.01 \\
Thiamin (mg) & $0.24(0.18)$ & $0.23(0.19)$ & 0.49 \\
Riboflavin (mg) & $0.33(0.25)$ & $0.32(0.26)$ & 0.65 \\
Vitamin C (mg) & $23(12)$ & $21(11)$ & 0.02 \\
Calcium (mg) & $118(45)$ & $113(42)$ & 0.02 \\
Iron (mg) & $2.4(0.9)$ & $2.3(0.9)$ & 0.01 \\
\hline
\end{tabular}

${ }^{*}$ Mean (standard deviation). Cod liver oil and vitamin/mineral supplements are included in the nutrient calculations. † Student's $t$-test. in the final model. Degree of urbanisation and geographic region were significant only when one of them was included at a time. Degree of urbanisation was included in the final model, as this variable was considered to be most relevant. Paternal education was significantly associated with no daily use of sweetened drinks even in the multivariate analysis. However, there was a strong correlation between maternal and paternal education and furthermore many extra data were missing $(n=166)$ when paternal education was included; thus only maternal education was included in the final model.

A multiple logistic regression analysis was also applied for no daily use of sugar-sweetened squash (data not shown). This analysis gave comparable results as for sweetened drinks, except for a significant positive trend that was found for maternal education.

\section{Discussion}

Data from this first national dietary survey among Norwegian infants showed that $36 \%$ were still being breast-fed at 12 months, and that maternal factors such as

Table 5 Crude and adjusted odds ratio (OR) (and 95\% confidence interval (CI)) for no daily use of sweetened drinks at 12 months according to maternal and infant characteristics*

\begin{tabular}{|c|c|c|c|}
\hline \multirow[b]{2}{*}{ Characteristic } & \multicolumn{3}{|c|}{ No daily use of sweetened drinks at 12 months } \\
\hline & $n(\%) \dagger$ & Crude OR $(95 \% \mathrm{Cl})$ & Adjusted OR $(95 \% \mathrm{Cl}) \ddagger$ \\
\hline \multicolumn{4}{|l|}{ Maternal age (years) } \\
\hline$<25$ & $143(65)$ & 1.00 & 1.00 \\
\hline $25-34$ & $824(67)$ & $1.09(0.80-1.47)$ & $1.26(0.90-1.77)$ \\
\hline$\geq 35$ & $192(64)$ & $0.98(0.68-1.41)$ & $1.30(0.85-1.99)$ \\
\hline$P$ for trend§ & & 0.82 & \\
\hline \multicolumn{4}{|l|}{ Maternal education (years) } \\
\hline$\leq 10$ & $100(59)$ & 1.00 & 1.00 \\
\hline $11-12$ & 457 (63) & $1.19(0.85-1.68)$ & $0.99(0.70-1.41)$ \\
\hline$\geq 13$ & $602(70)$ & $1.62(1.15-2.26)$ & $1.12(0.77-1.61)$ \\
\hline$P$ for trend§ & & $<0.01$ & 0.36 \\
\hline \multicolumn{4}{|l|}{ Breast-feeding at 12 months } \\
\hline No & $703(63)$ & 1.00 & 1.00 \\
\hline Yes & $456(71)$ & $1.42(1.15-1.75)$ & $1.33(1.07-1.66)$ \\
\hline$P q$ & & $<0.01$ & $<0.01$ \\
\hline \multicolumn{4}{|l|}{ Number of siblings } \\
\hline 0 & $515(73)$ & 1.00 & 1.00 \\
\hline 1 & $397(64)$ & $0.63(0.50-0.80)$ & $0.59(0.46-0.75)$ \\
\hline$\geq 2$ & $247(57)$ & $0.49(0.38-0.63)$ & $0.47(0.35-0.63)$ \\
\hline$P$ for trend§ & & $<0.001$ & $<0.001$ \\
\hline \multicolumn{4}{|l|}{ Maternal smoking at 6 months } \\
\hline No & $908(68)$ & 1.00 & 1.00 \\
\hline Yes & $251(58)$ & $0.64(0.51-0.81)$ & $0.72(0.57-0.91)$ \\
\hline$P q$ & & $<0.001$ & $<0.01$ \\
\hline \multicolumn{4}{|l|}{ Degree of urbanisation } \\
\hline$<2000$ inhabitants & $375(62)$ & 1.00 & 1.00 \\
\hline 2000-19999 inhabitants & $249(65)$ & $1.13(0.87-1.48)$ & $1.09(0.83-1.43)$ \\
\hline $20000-99999$ inhabitants & $151(62)$ & $1.04(0.76-1.41)$ & $0.94(0.69-1.28)$ \\
\hline$\geq 100000$ inhabitants & $384(74)$ & $1.75(1.36-2.26)$ & $1.49(1.14-1.94)$ \\
\hline$P$ for trend§ & & $<0.001$ & 0.01 \\
\hline
\end{tabular}

${ }^{*} n=1758$.

† Number of infants not receiving sweetened drinks daily within current independent variable, percentages in parentheses.

$\ddagger$ ORs and $95 \%$ Cls adjusted for all other variables in the table.

$\S$ Test for linear trend.

I Likelihood ratio test. 
age, education and smoking were significantly associated with breast-feeding at this age. Furthermore, allergy/asthma among family members, which is less examined in relation to breast-feeding, was also associated with breast-feeding at 12 months. Apart from the difference in intake of milk, breast-fed infants had a lower intake of sweetened drinks and 30\% higher odds of no daily use of sweetened drinks compared with nonbreast-fed infants.

The large number of participants and the sampling method are important strengths of the survey. The response rate was acceptable (66\%), but lower than in the 6-month survey (80\%). However, no indications of differences between responders and those invited to participate were found regarding maternal age, geographic region or infant gender. Moreover, when comparing data on the responders with available data on all Norwegian births in 1998, there were no indications of differences regarding infant gender, gestational age, parity, geographic region or maternal civil status, and only small differences in maternal age and educational level. The responders are considered representative for 12-month-old Norwegian infants and their mothers. Many food and drink items, nutrients and other variables were analysed and concern with multiple comparisons must be kept in mind when drawing conclusions. Moreover, with our relatively large number of subjects, even small differences may be significant, and the clinical relevance of the findings must be considered, especially those in Tables 3 and 4. Dietary assessments among infants are complicated by the fact that dietary habits change rapidly in infancy, parents may share the responsibility for the child with other adults (e.g. in day care), and finally not all food served to the infants is consumed, some is wasted. All of these factors may limit the ability of the SFFQ to estimate dietary intakes. However, in the validation study of the $\mathrm{SFFQ}^{20}$ we found acceptable estimates for average intakes of foods, drinks and nutrient densities, while most of the absolute intakes of nutrients were overestimated.

A total of $36 \%$ of infants being breast-fed at 12 months is higher than reported from other industrialised countries $^{8,22-24}$. It is also among the highest proportions reported in $\mathrm{Norway}^{25}$, as records from three maternity hospitals have shown a decline in breast-feeding for 12 months from about 50\% in 1860 to 30\% in 1920 and 10\% in 1940 , and an increase from almost none in 1960 to $10 \%$ in 1980 .

For breast-feeding at 12 months, significant positive trends were found for maternal age, education and degree of urbanisation, and a significant negative association was found for maternal smoking. These results are in agreement with findings from studies in other industrialised countries ${ }^{22-24,26-30}$ and comparable to our results on factors associated with breast-feeding at 6 months ${ }^{3}$. Most studies have analysed factors associated with breast-feeding duration shorter than 12 months; however, the Third National Health and Nutrition Examination Survey (NHANES 11l) showed in a univariate analysis that the rate of breast-feeding at 12 months (9\%) among US infants varied by maternal age, education, smoking, region and other factors such as ethnicity ${ }^{24}$. In the present survey, the odds of being breast-fed at 12 months were about $40 \%$ higher for infants with allergy/asthma among family members than for those not affected, whereas for breastfeeding at 6 months we did not find a significant association with this variable ${ }^{3}$. This might indicate that allergy/asthma in the family motivates longer-term breastfeeding. We did not find a significant positive trend of breast-feeding at 12 months and number of siblings as we found for breast-feeding at 6 months ${ }^{3}$. Data from other Western countries show inconsistent results on the association between parity and breast-feeding ${ }^{29}$.

Intakes of some foods, such as meat and fish, were significantly lower among breast-fed compared with nonbreast-fed infants. However, the largest differences in consumption between breast-fed and non-breast-fed infants were seen for drinks. In addition to the expected finding of considerably lower intakes of cow's milk and infant formula among breast-fed infants, they also had a significantly lower intake of sugar-sweetened drinks, while their intake of water was higher. Others have observed comparable results among younger infants ${ }^{5-7}$. In the Copenhagen Cohort Study, apart from the difference in milk intake, infants partially breast-fed at 9 months also had a significantly lower intake of meat and meat products than infants not breast-fed at this age ${ }^{5}$. In the study by Nielsen et al. ${ }^{6}, 10$-month-old infants breastfed for at least 7 months had also significantly lower intakes of cow's milk and meat-containing dishes compared with those breast-fed for $<7$ months. Furthermore, the percentage of energy from sweetened beverages was $1.8 \%$ for those breast-fed for at least 7 months and $2.7 \%$ for those breast-fed for $<7$ months; however, the difference was not significant in this study of 339 infants. Among 8-month-old British infants, a lower proportion of consumers of squash and higher proportions of consumers of water and fruit juice were found among those breast-fed for at least 4 weeks, compared with those breast-fed for shorter or those never breast$\mathrm{fed}^{7}$. Moreover, duration of breast-feeding remained associated with use of squash and water, but not with use of fruit juice, in a multivariate analysis adjusting for sociodemographic factors.

Slightly different intakes of nutrients from foods and drinks other than milk were observed among breast-fed and non-breast-fed infants. However, the clinical relevance of these differences is difficult to interpret. The largest difference in daily intakes of nutrients was seen for added sugars; breast-fed infants had 16\% lower intake compared with non-breast-fed infants, and as no added sugars came from milk, these figures represent their total daily intakes of added sugars. We are not aware of other 
studies that have reported intakes of added sugars among breast-fed and non-breast-fed infants. In the Avon Longitudinal Study of Pregnancy and Childhood (ALSPAC) in south-west England, a lower daily intake of total sugars was observed among 8-month-old breast-fed infants compared with non-breast-fed infants ${ }^{9}$. However, as total sugars include naturally occurring mono- and disaccharides in foods and drinks, these figures are not directly comparable with our data. Among the 8-month-old British infants, daily intakes of nearly all macro- and micronutrients were lower among breast-fed compared with non-breast-fed infants (breast milk intake was included in the calculations). Differences in nutrient density were, however, not evaluated. When we evaluated differences in nutrient density of foods and drinks other than milk, we found that breast-fed infants, apart from keeping a lower energy percentage of added sugars, achieved a slightly higher nutrient density of some vitamins, minerals and fibre compared with non-breast-fed infants.

Breast-fed infants had about 30\% higher odds than nonbreast-fed infants of no daily use of sweetened drinks. Furthermore, a negative trend of no daily use of sweetened drinks was seen for number of siblings, a positive trend was seen for degree of urbanisation and a negative association was found for maternal smoking. We observed a tendency of an interaction between number of siblings and degree of urbanisation, which needs to be studied further. Maternal age and education were not significantly associated with no daily use of sweetened drinks. However, a significant positive trend was found for maternal education in the multivariate analysis of no daily use of squash. Among British infants ${ }^{7}$ and 18-montholds $^{31}$, multivariate analyses showed that breast-feeding duration and maternal education were significantly associated with use of squash at 8 months $^{7}$, and the presence of older siblings and maternal age were significantly associated with use of squash at 18 months ${ }^{31}$. We found a negative trend of no daily use of sweetened drinks and number of siblings, and a possible explanation could be that suggested by North et al. ${ }^{32}$. Among British 3-year-olds, they found that having older siblings was significantly associated with higher scores on 'junk' food and 'snack' food components, and pointed out that older siblings might have introduced 'children's foods' such as biscuits, sweets and squash into the household.

In conclusion, maternal age, education and smoking were important factors for breast-feeding at 12 months. Furthermore, higher odds of being breast-fed at this age were found for infants with family members affected with allergy/asthma than for those not affected. Some dietary differences were observed between breast-fed and nonbreast-fed infants apart from intake of milk. In particular, breast-fed infants had lower intakes of sweetened drinks and added sugars. Furthermore, breast-fed infants had higher odds of no daily use of sweetened drinks than non-breast-fed infants. From a public health perspective, continued breast-feeding promotion is needed to reduce inequalities in breast-feeding. Furthermore, efforts to prevent high intakes of sweetened drinks and added sugars should start in infancy.

\section{Acknowledgements}

We thank Kari Lund-Larsen at the Norwegian Food Control Authority for her contribution in developing the survey design and the SFFQ, and Elin Bjørge Løken at the Institute for Nutrition Research, University of Oslo for her contribution in establishing the final food database for this survey. This work was supported by the former National Council on Nutrition and Physical Activity (now part of the Directorate for Health and Social Affairs), the Norwegian Food Control Authority and by a grant from the Research Council of Norway.

\section{References}

1 National Council on Nutrition and Physical Activity. Anbefalinger for spedbarnsernoering [Infant Feeding Recommendations]. Oslo: National Council on Nutrition and Physical Activity, 2001 (in Norwegian).

2 World Health Organization. The World Health Organization's infant feeding recommendation. Weekly Epidemiological Record 1995; 70: 119-29.

3 Lande B, Andersen LF, Bærug A, Trygg KU, Lund-Larsen K, Veierød MB, et al. Infant feeding practices and associated factors in the first six months of life: The Norwegian Infant Nutrition Survey. Acta Paediatrica 2003; 92: 152-61.

4 Heinig MJ, Nommsen LA, Peerson JM, Lönnerdal B, Dewey KG. Energy and protein intakes of breast-fed and formula-fed infants during the first year of life and their association with growth velocity: the DARLING Study. American Journal of Clinical Nutrition 1993; 58: 152-61.

5 Michaelsen KF. Nutrition and growth during infancy. The Copenhagen Cohort Study. Acta Paediatrica 1997; 86(Suppl. 420): 1-36.

6 Nielsen GA, Thomsen BL, Michaelsen KF. Influence of breastfeeding and complementary food on growth between 5 and 10 months. Acta Paediatrica 1998; 87: 911-7.

7 North K, Emmett P, Noble S, the ALSPAC Study Team. Types of drinks consumed by infants at 4 and 8 months of age: sociodemographic variations. Journal of Human Nutrition and Dietetics 2000; 13: 71-82.

8 Atladottir H, Thorsdottir I. Energy intake and growth of infants in Iceland - a population with high frequency of breast-feeding and high birth weight. European Journal of Clinical Nutrition 2000; 54: 695-701.

9 Noble S, Emmett P, the ALSPAC Study Team. Food and nutrient intake in a cohort of 8-month-old infants in the south-west of England in 1993. European Journal of Clinical Nutrition 2001; 55: 698-707.

10 Armstrong J, Reilly JJ, the Child Health Information Team. Breastfeeding and lowering the risk of childhood obesity. Lancet 2002; 359: 2003-4.

11 Dewey KG. Is breast-feeding protective against child obesity? Journal of Human Lactation 2003; 19: 9-18.

12 Ludwig DS, Peterson KE, Gortmaker SL. Relation between consumption of sugar-sweetened drinks and childhood obesity: a prospective, observational analysis. Lancet 2001; 357: 505-8. 
13 Johnson RK, Frary C. Choose beverages and foods to moderate your intake of sugars: the 2000 dietary guidelines for Americans - what's all the fuss about? Journal of Nutrition 2001; 131(Suppl.): 2766-71.

14 Sheiham A. Dietary effects on dental diseases. Public Health Nutrition 2001; 4: 569-91.

15 Nordic Council of Ministers. Nordiska näringsrekommendationer 1996 [Nordic Nutrition Recommendations 1996. Report 1996: 28. Copenhagen: Nordic Publishing House, 1996 (in Swedish).

16 World Health Organization (WHO). Diet, Nutrition and the Prevention of Chronic Diseases. Report of a Joint WHO/FAO Expert Consultation. WHO Technical Report Series No. 916. Geneva: WHO, 2003.

17 Pollestad ML, Øverby NC, Andersen LF. Kostbold blant 4åringer. Landsomfattende kostholdsundersøkelse UNGKOST2000 [Diet among 4-year-olds. National Dietary Survey UNGKOST-2000]. Oslo: Directorate for Health and Social Affairs, 2002 (in Norwegian).

18 Rampersaud GC, Bailey LB, Kauwell GP. National survey beverage consumption data for children and adolescents indicate the need to encourage a shift toward more nutritive beverages. Journal of the American Dietetic Association 2003; 103: 97-100.

19 Statistics Norway. Undersøkelse om kosthold blant 12-måneder gamle spedbarn [Dietary Survey among 12-month-old Infants]. Note 1999/64. Oslo: Statistics Norway, 1999 (in Norwegian).

20 Andersen LF, Lande B, Arsky GH, Trygg K. Validation of a semi-quantitative food-frequency questionnaire used among 12-month-old Norwegian infants. European Journal of Clinical Nutrition 2003; 57: 881-8.

21 National Nutrition Council and the Food Control Authority. Den store matvaretabellen 1995 [Food Composition Table 1995]. Oslo: Universitetsforlaget, 1995 (in Norwegian).

22 Riva E, Banderali G, Agostoni C, Silano M, Radaelli G,
Giovannini M. Factors associated with initiation and duration of breastfeeding in Italy. Acta Paediatrica 1999; 88: 411-5.

23 Dulon M, Kersting M, Schach S. Duration of breastfeeding and associated factors in Western and Eastern Germany. Acta Paediatrica 2001; 90: 931-5.

24 Li R, Ogden C, Ballew C, Gillespie C, Grummer-Strawn L. Prevalence of exclusive breastfeeding among US infants: the Third National Health and Nutrition Examination Survey (Phase II, 1991-1994). American Journal of Public Health 2002; 92: $1107-10$.

25 Liestøl K, Rosenberg M, Walløe L. Breast-feeding practice in Norway 1860-1984. Journal of Biosocial Science 1988; 20: 45-58.

26 Michaelsen KF, Larsen PS, Thomsen BL, Samuelson G. The Copenhagen cohort study on infant nutrition and growth: duration of breast feeding and influencing factors. Acta Paediatrica 1994; 83: 565-71.

27 Rogers IS, Emmett PM, Golding J. The incidence and duration of breast feeding. Early Human Development 1997; 49(Suppl.): 45-74.

28 Foster K, Lader D, Cheesbrough S. Infant Feeding 1995. London: HMSO, 1997.

29 Scott JA, Binns CW. Factors associated with the initiation and duration of breastfeeding: a review of the literature. Breastfeeding Review 1999; 7: 5-16.

30 Horta BL, Kramer MS, Platt RW. Maternal smoking and the risk of early weaning: a meta-analysis. American Journal of Public Health 2001; 91: 304-7.

31 Northstone K, Rogers I, Emmett P, the ALSPAC Study Team. Drinks consumed by 18-month-old children: are current recommendations being followed? European Journal of Clinical Nutrition 2002; 56: 236-44.

32 North K, Emmett P, the ALSPAC Study Team. Multivariate analysis of diet among three-year-old children and associations with socio-demographic characteristics. European Journal of Clinical Nutrition 2000; 54: 73-80. 